\title{
К ВОПРОСУ РАЗРАБОТКИ ПЛАТФОРМЫ СОЦИАЛЬНОЙ СЕТИ НА ОСНОВЕ ГЕОГРАФИЧЕСКИХ КАРТ
}

\section{TO THE QUESTION OF PLATFORM \\ DEVELOPMENT SOCIAL NETWORK BASED ON GEOGRAPHIC MAPS}

\section{A. Mukhamedzyanov}

R. Nabiev

Summary. The work is devoted to the development of a software product that will combine the concepts of a geographical map, social networks and various geoservices. The requirements for the product being developed from the point of view of user requests were identified, as well as the selection of development tools and the reasoning for their choice.

Keywords: geodata, social networks, geographical maps.
Мухамедзянов Амир Ильдарович

Казанский национальный исследовательский технологический университет, г. Казань

therealloathing@gmail.com

Набиев Рафит Ренатович

К.х.н., дочент, Казанский начиональный исследовательский технологический университет,

г. Казань

nabievrafit@mail.ru

Аннотация. Работа посвящена разработке программного продукта, который будет совмещать концепты географической карты, социальных сетей и различных геосервисов. Были обозначены требования к разрабатываемому продукту с точки зрения запросов пользователей, а также произведен подбор инструментов разработки и аргументация их выбора.

Ключевые слова: геоданные, социальные сети, географические карты.

ботки. В настоящей работе определяются основные требования к создаваемому сервису, а также производится выбор инструментальных средств разработки.

\section{Теоретическая часть}

На рынке мобильных приложений существует несколько решений, которые схожи по функционалу к разрабатываемому нами сервису.

Zenly (куплен компанией Snap летом 2017 г.) - социальная сеть с применением географических карт. Функционал Zenly: 1. возможность добавления/удаления друзей; 2. встроенный мессенджер; 3. доступ к географической карте, на которой отображается местоположение всех добавленных друзей - есть возможность включения режима невидимости на карте; 4. отображение скорости движения друзей, анализ местоположения всех пользователей приложением, уровень заряда батареи гаджетов друзей.

Геопозиция пользователей Zenly обновляется постоянно, даже если приложение не запущено, так что координаты будут всегда актуальными. Несмотря на весь перечисленный функционал и применение потенциально прорывного направления (использование географических карт), Zenly не может похвастаться популярностью среди пользователей - многие устанавливают приложение и через определенное время удаляют Zenly.

Для выполнения поставленной цели необходи грамотно подойти к выбору методов и средств разра- 
Мессенджеры Telegram обладает функцией live-трансляции текущей геопозиции, однако работа данной функции организована очень слабо. Например, ручная организация каждой трансляции, ограничения по времени для трансляций и т.д. В приложении WhatsApp можно лишь поделиться геопозицией с собеседником - функция выглядит рудиментарной, так как существуют более удобные методы передачи текущего положения на карте.

В силу перечисленных выше причин, в настоящее время направление использования географических карт в приложениях для социальных сетей не развито в должной мере.

\section{Практическая часть}

Основные положения разрабатываемой платформы социальной сети на основе географических карт следующие - именно они обеспечат конкурентные преимущества перед другими похожими продуктами.

Во-первых, отображение географических координат не должно ограничиваться только на добавленных друзьях. Речь не идет об отображении геоданных всех пользователей, что обусловило бы огромные объемы информационного мусора. Географическая карта платформы должна отображать информацию о доступных сервисах на объектах, которые интересны пользователю.

Во-вторых, необходимо, чтобы пользователь мог самостоятельно выделять круг своих интересов, исходя из этой информации платформа в дальнейшем отображает информацию об объектах на карте. Другими словами, наша цель заключается в объединении в одну оболочку нескольких приложений - это поможет сэкономить как время пользователя (отпадает необходимость использования сторонних сервисов), так и память устройства.

В-третьих, пользователь должен иметь возможность поиска интересующих сервисов по карте платформы.

Перечисленные требования с одной стороны повышают ценность разрабатываемого программного продукта, с другой - предполагают существенные трудности. Идея объединения отдельных сервисов в единый продукт неплоха, но на данном этапе практически не реализуема, так как все сервисы функционируют отдельно и имеют свои базы пользователей. Поэтому лучшим решением данной проблемы представляется синхронизация сервисов и привязка их к аккаунту разрабатываемой платформы. Исходя из вышесказанного, предполагается разработка продукта, который будет представлять не только мессенджер и отображение геоданных друзей, но интегрированные миниприложения, использующие геоданные.

Далее перейдем к вопросам конструирования и выбора компонентов разработки платформы. В настоящее время существует множество языков программирования (C++, Java, C\#, Python и т.д.) [1-4], с помощью которых может быть реализовано выполнение поставленных выше задач. Мы предлагаем в качестве языка программирования использовать Python с фреймворком Django. Почему выбран именно Django: бесплатная доступность; легко читаемый код; большая база готовых, легко подключаемых библиотек; упор на разработку Web-приложений; использование MVC-шаблона для приложений и т.д. MVC-шаблон наилучшим образом подходит для нашего решения, т.к. наше приложение будет включать себя множество автономных модулей. Кроме того, такие крупные игроки, как Instagram, Google, YouTube, Pinterest, Mozilla и др. используют веб-фреймворк Django - это подтверждает надежность и востребованность языка программирования.

Первоначальная разработка Django как инструмента для работы новостных ресурсов сильно отразилась на его архитектуре: он предоставляет ряд средств, которые помогают в быстрой разработке Web-сайтов информационного характера [4]. Так, например, разработчику не требуется создавать контроллеры и страницы для административной части сайта. B Django есть встроенное приложение для управления содержимым, которое можно включить в любой сайт, сделанный на Django, и которое может управлять сразу несколькими сайтами на одном сервере. Административное приложение позволяет создавать, изменять и удалять любые объекты наполнения сайта, протоколируя все совершённые действия, и предоставляет интерфейс для управления пользователями и группами (с пообъектным назначением прав).

B Django уже есть собственный мощный гибкий инструмент для работы с геоданными - GeoDjango. GeoDjango - это встроенный модуль для Django, который превращает его в географическую Web-среду мирового класса [4]. GeoDjango стремится максимально упростить создание географических Web-приложений, таких как сервисы на основе определения местоположения. Функции GeoDjango:

- поля модели Django для геометрии OGC и растровых данных;

- расширения к ORM (от англ. Object-Relational Mapping, объектно-реляционное отображение, или преобразование) - технология программирования, которая связывает базы данных с концепциями объектно-ориентированных языков программирования; 
- слабосвязанные высокоуровневые интерфейсы Python для GIS-геометрии, растровых операций и обработки данных в различных форматах;

- редактирование геометрических полей из административной панели.

Также существуют готовые решения-библиотеки для GeoDjango, значительно упрощающие работу с ним, такие как Leaflet [4]. Leaflet - это лидирующая библиотека JavaScript с открытым исходным кодом для мобильных интерактивных карт. При относительно небольшом весе он имеет все картографические функции, которые когда-либо нужны большинству разработчиков. Leaflet разработан с учетом простоты, производительности и удобства использования. Он эффективно работает на всех основных настольных и мобильных платформах, может быть расширен за счет множества плагинов, имеет красивый, простой в использовании и хорошо документированный программный интерфейс приложения (API, от англ. application programming interface) и простой, читаемый исходный код, в который приятно вносить вклад.

GeoDjango вместе c Leaflet организуют эффективную комбинацию для разработки приложения с использованием географических карт. Когда как Leaflet предоставит клиентскую сторону пользовательского интерфейса (фронтенд, от англ. front-end), удобный функционал для отображения и рисования карт, GeoDjango обеспечит крепкий программно-аппаратную часть сервиса (бэкенд, от англ. back-end) и эффективное хранение геоданных в самой программе на PostgreSQL.

Вероятнее всего, возникнет проблема с локализацией обозначений мест не на территории Российской Федерации. С переводом обозначений на русский язык, если понадобится, может помочь пакет OpenStreetMap для Django. OpenStreetMap - некоммерческий Web-картографический проект по созданию силами пользователей Интернета подробной свободной и бесплатной географической карты мира. Для создания карт используются данные с персональных GPS-трекеров, аэрофотографии, видеозаписи, спутниковые снимкии панорамы улиц, предоставленные некоторыми организациями.

В итоге намечено: 1. фундамент платформы - язык Python+Django; 2. база данных - PostgreSQL; 3. бэкенд API для карт - GeoDjango; 4. фронтенд API для карт Leaflet; 5. рендеринг, локализация, подробные данные карт - OpenStreetMap.

Следующая часть работы - техническая, которая будет изложена в последующих публикациях. Будут описаны сам процесс разработки приложения, решение возникших проблем и апробация результатов работы.

\section{ЛИТЕРАТУРА}

1. Литвиненко Н. А. Технология программирования на C++. Win32 API-приложения / Н. А. Литвиненко // СПб.: БХВ-Петербург, 2010. - 288 с.

2. Жарков B. A. Visual C\# 2005 в учебе, науке и технике (+ CD-ROM) / B. А. Жарков // Москва: Жарков Пресc, 2006. — 818 C.

3. Любанович Б. Простой Python. Современный стиль программирования / Б. Любанович // СПб.: Питер, 2016. - 480 c.

4. Форсье Д. Django. Разработка веб-приложений на Python / Д. Форсье, П. Биссекс, У. Чан // Москва: Символ-Плюс, 2009. — 458 с. 